08

\title{
Влияние температуры отжига на микроструктуру и морфологию пленок TiN, синтезированных методом дуального магнетронного распыления
}

\author{
(ㄱ С.В. Зайцев, В.С. Ващилин, Д.С. Прохоренков, М.В. Лимаренко, Е.И. Евтушенко
}

Белгородский государственный технологический университет им. В.Г. Шухова, 308012 Белгород, Россия

e-mail: sergey_za@mail.ru

(Поступило в Редакцию 3 марта 2017 г. В окончательной редакции 13 фревраля 2018 г.)

Пленки TiN, синтезированные на подложках лейкосапфира методом дуального магнетронного распыления, подвергли последующему отжигу в вакууме при $600,700,800$ и $900^{\circ} \mathrm{C}$ в течение 2 min. Микроструктуру и морфологию пленок при различных температурах исследованы методами рентгеновской дифракции и сканирующей электронной микроскопии. Установлено, что отжиг влияет на изменения в микроструктуре, текстуре, размере зерна и шероховатости пленок TiN.

DOI: $10.21883 /$ JTF.2018.08.46313.2234

\section{Введение}

Исследования структурных и морфологических изменений, происходящих в тонких пленках при отжиге, представляют огромный интерес как для понимания фундаментальных и релаксационных процессов, проистекающих в этих пленках, так и для решения разнообразных практических задач. Изучение происходящих в тонких пленках процессов изменения структур, возникающих при термическом воздействии, имеет большое прикладное значение.

Пленки нитрида титана $(\mathrm{TiN})$ используют в качестве твердых износостойких покрытий режущего инструмента, контактных слоев солнечных батарей, диффузионных барьеров в микроэлектронике, декоративных и антикоррозионных покрытий. Это обусловлено тем, что эти пленки обладают высокой твердостью и высоким модулем упругости, хорошей термической и химической стабильностью, низким коэффициентом трения, биосовместимостью, высоким сопротивлением коррозии и износостойкостью [1-5].

В настоящей работе представлены результаты исследования влияния температуры отжига на микроструктуру и морфологию пленок TiN, синтезированных на подложках лейкосапфира, методом дуального магнетронного распыления.

\section{Методика исследования}

Пленки TiN были получены в установке вакуумного напыления QUADRA 500TM методом дуального магнетронного распыления титановой мишени в атмосфере $\mathrm{Ar}-\mathrm{N}_{2}$ на лейкосапфировые подложки по методике, описанной нами ранее [6]. Температурному отжигу были подвергнуты пленки TiN толщиной $1.9 \mu \mathrm{m}$.

Высокотемпературный отжиг тонких пленок TiN проводили в технологической установке STERTP 150 при температуре 600, 700, 800 и $900^{\circ} \mathrm{C}$. Камеру установки откачивали до давления ниже $260 \mathrm{~Pa}$, затем осушали потоком сухого азота в течение $10 \mathrm{~min}$. Далее камеру установки откачивали до давления $260 \mathrm{~Pa}$ и проводили градиентный фотонный отжиг пленок в течение $2 \mathrm{~min}$. Образцы устанавливали на тепловыравнивающие диски из графита, обеспечивающие однородность нагрева. Температуры процесса отжига пленок измеряли с помощью пирометра.

Кристаллическая структура и преимущественная ориентация тонких пленок TiN исследовались с помощью рентгеновской дифракции (ARL X'TRA, ThermoTechno) B режиме асимметричной компланарной съемки со скользящим углом падения $\alpha=3^{\circ}(\theta$-scan) для исключения пиков от подложки. Для расшифровки дифрактограмм использовалась база данных Международного центра дифракционных данных JCPDF. Индексирование пиков, а также определение параметра $a$ элементарной ячейки, осуществлялись по данным моделирования дифракции от кристаллического TiN.

Размеры областей когерентного рассеивания рентгеновских лучей $\left(L_{\mathrm{CDA}}\right)$, т. е. характеристические размеры зерна, для пиков (111) и (220) рассчитывались по формуле Шеррера

$$
L_{\mathrm{CDA}}=\frac{k \lambda}{\beta \cos \theta}
$$

где $k=0.9-$ усредненная константа; $\lambda=$ $=0.1541744 \mathrm{~nm}-$ длина волны рентгеновского излучения; $\beta$ - полная ширина рефлекса на его полувысоте в радианах (по шкале $2 \theta$ ); $\theta$ - угол, под которым наблюдается пик дифракции [7]. При расчетах по формуле (1) вклады в ширину пиков от напряжений в зернах не учитывались.

Морфологию поверхности, фрактограммы и толщину пленки определяли с помощью сканирующего электронного микроскопа (TESCAN MIRA 3 LMU). Мик- 


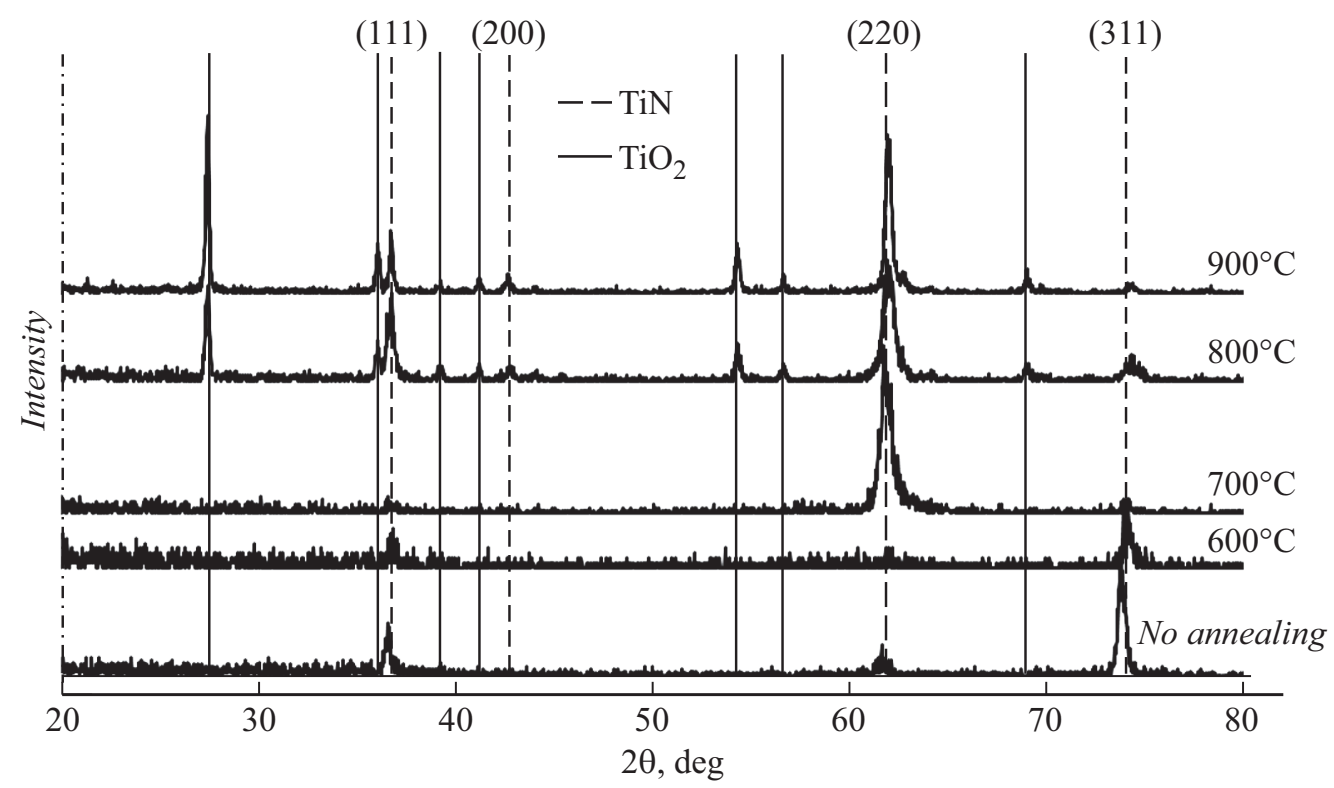

Рис. 1. Дифрактограммы (режим $\theta$-scan) пленок нитрида титана, термически обработанных при различных температурах.
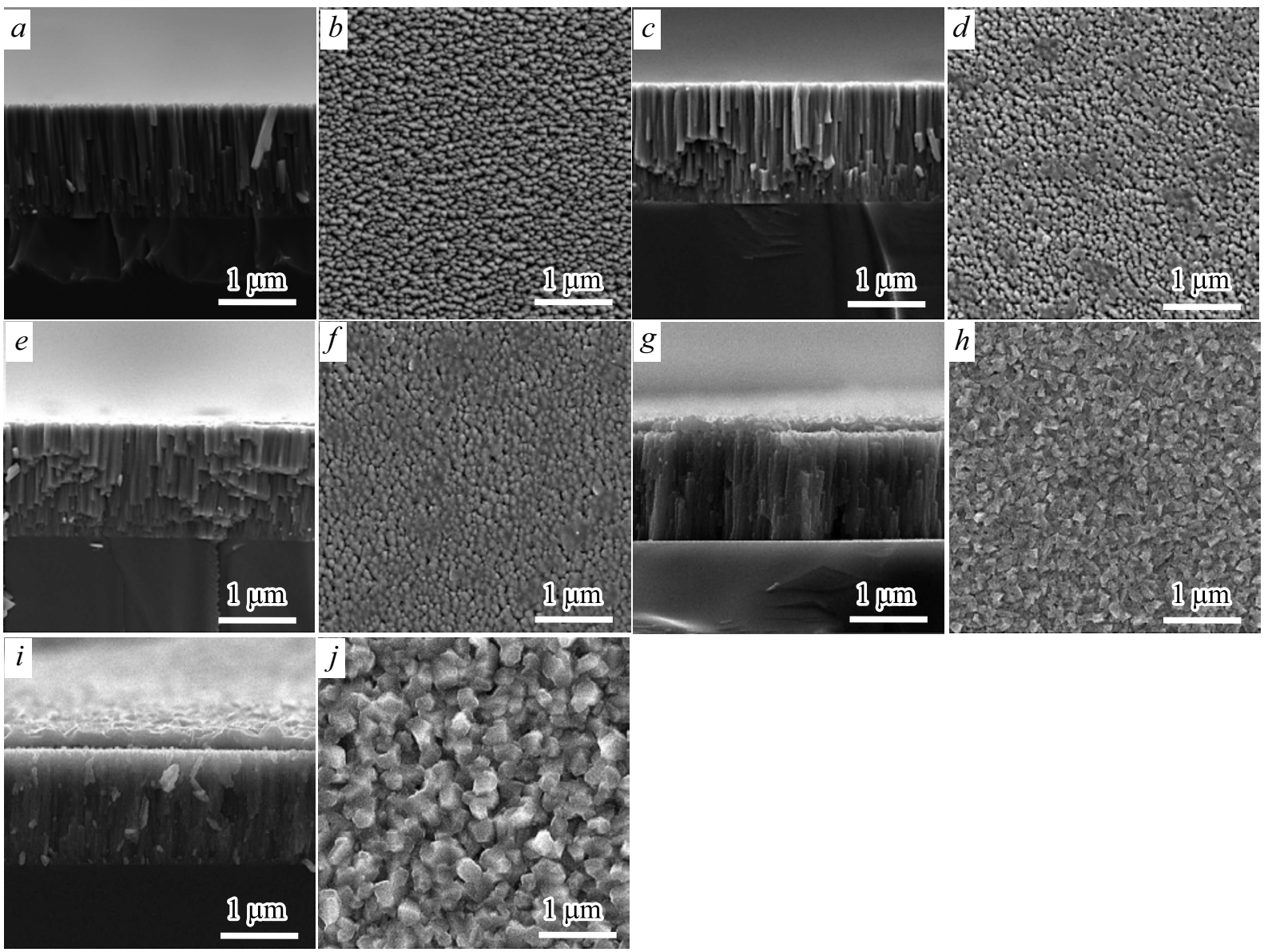

Рис. 2. Морфология поверхности и фрактограммы пленок TiN, термически обработанных при различных температурах: без отжига $(a, b), 600(c, d), 700(e, f), 800(g, h), 900^{\circ} \mathrm{C}(i, j)$. 

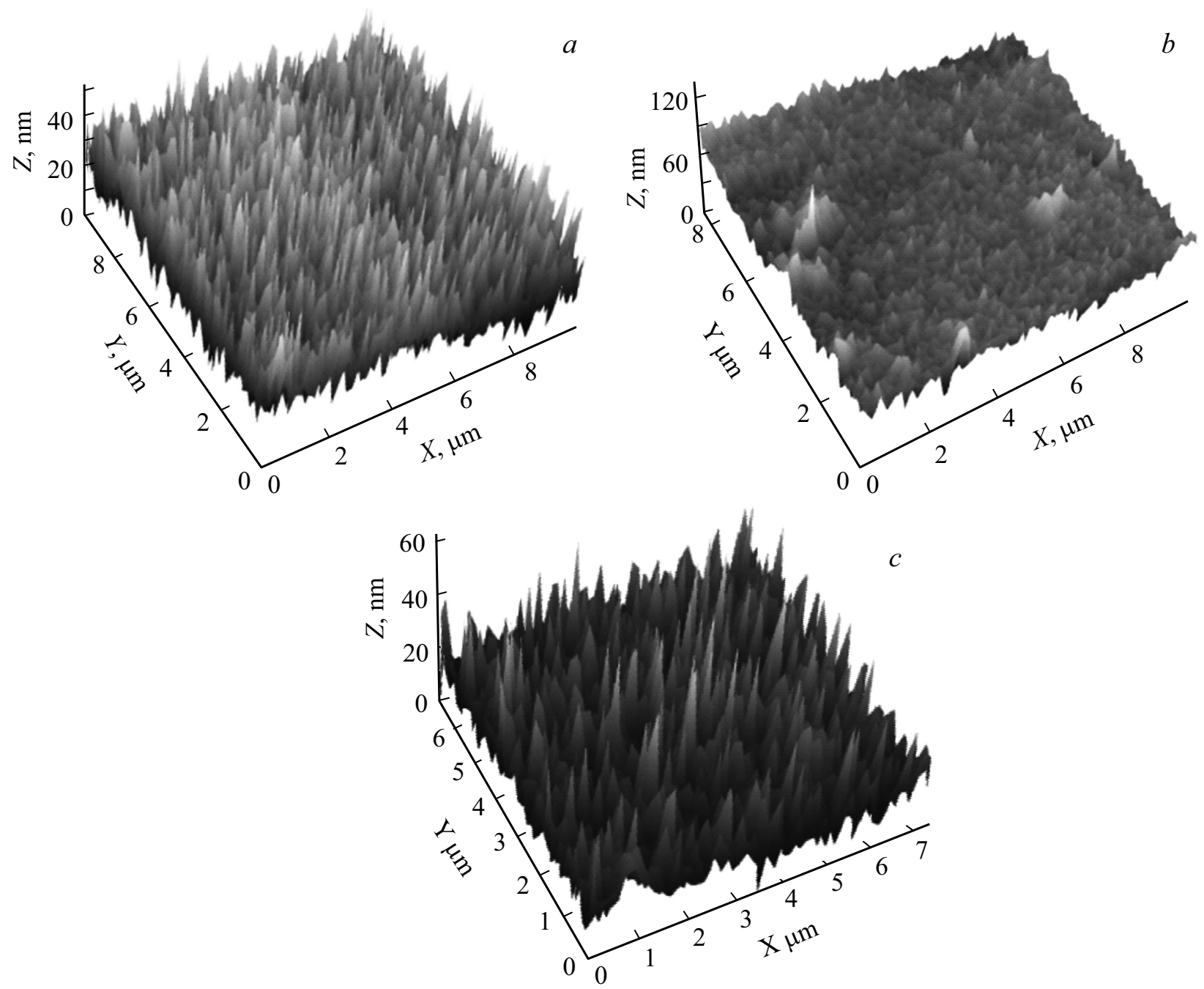

Pис. 3. Топология поверхности пленок TiN: без отжига $(a), 600(b), 700^{\circ} \mathrm{C}(c)$.

рорельеф поверхности тонких пленок TiN исследовали с помощью сканирующего зондового микроскопа NanoEducator фирмы NT MDT.

\section{Результаты исследования}

На рис. 1 представлены дифрактограммы пленок TiN до и после отжига. Пленки TiN после магнетронного распыления имеют поликристаллическую структуру с ориентацией по кристаллографическим направлениям (111), (220) и (311). Отжиг в вакууме при $600^{\circ} \mathrm{C}$ в течение 2 min приводит к уменьшению интенсивности рефлексов от (111), (220) и (311) плоскостей. В результате отжига при $700^{\circ} \mathrm{C}$ увеличивается интенсивность рефлекса от (220) плоскости почти без рефлекса от (111) плоскости, что указывает на сильную (220) текстуру. После отжига пленки при 800 и $900^{\circ} \mathrm{C}$ вновь наблюдается поликристаллическая структура. Кроме того, на поверхности покрытия $\mathrm{TiN}$ начинает расти слой оксида титана $\left(\mathrm{TiO}_{2}\right)$ в фазе рутила.

Наблюдаемые изменения преимущественной ориентации пленки TiN, по-видимому, связано с температурой отжига, указывая на переориентацию зерна. В результате за счет отжига происходит перегруппировка атомов путем диффузии в пленке и тем самым отжиг улучшает степень кристалличности образцов $[8,9]$. Как уже говорилось в работе [10], в области низких температур тепловая энергия является благоприятной для роста (111) плоскостей, в результате (111) плоскость растет гораздо быстрее, чем (200) плоскость. С повышением температуры до $700^{\circ} \mathrm{C}$ количество тепловой энергии выделяется достаточно для роста (220) плоскости, что приводит к изменению преимущественной ориентации от (111) к (220). При дальнейшем повышении температуры пленки TiN приобретают поликристаллическую структуру с (111), (200), (220) и (311) ориентацией. Это свидетельствует о том, что отжиг обеспечивает 
Характеристики дифракционных рефлексов от покрытий TiN

\begin{tabular}{|c|c|c|c|c|c|c|}
\hline Условия отжига & $\begin{array}{l}\text { Угол дифракции } \\
(\text { по шкале } 2 \theta),\end{array}$ & Плоскость & $\begin{array}{c}\text { Полная ширина } \\
\text { на полувысоте } \\
\text { (по шкале } 2 \theta), ~\end{array}$ & $\begin{array}{l}\text { Интенсивность, } \\
\text { pulse/s }\end{array}$ & $a, \mathrm{~nm}$ & $\begin{array}{c}L_{\mathrm{CDA}}, \\
\mathrm{nm}\end{array}$ \\
\hline & 36.56 & 111 & 0.425 & 80 & \multirow{2}{*}{0.4251} & 24.68 \\
\hline Без отжига & 61.64 & 220 & 0.565 & 39 & & 18.89 \\
\hline $600^{\circ} \mathrm{C}$ & 36.82 & 111 & 0.5 & 43 & \multirow{2}{*}{0.4249} & 19.52 \\
\hline $2 \mathrm{~min}$ & 61.96 & 220 & 0.56 & 21 & & 17.40 \\
\hline $700^{\circ} \mathrm{C}$ & 36.58 & 111 & 0.675 & 21 & \multirow{2}{*}{0.4240} & 15.44 \\
\hline $2 \min$ & 61.8 & 220 & 0.785 & 476 & & 12.94 \\
\hline $800^{\circ} \mathrm{C}$ & 36.72 & 111 & 0.48 & 173 & \multirow{3}{*}{0.4240} & 20.85 \\
\hline $2 \mathrm{~min}$ & 42.64 & 200 & 0.47 & 23 & & 23.28 \\
\hline & 62.08 & 220 & 0.775 & 260 & & 12.25 \\
\hline $900^{\circ} \mathrm{C}$ & 36.72 & 111 & 0.33 & 142 & \multirow{3}{*}{0.4240} & 30.33 \\
\hline $2 \min$ & 42.72 & 200 & 0.395 & 48 & & 28.56 \\
\hline & 61.96 & 220 & 0.47 & 481 & & 20.73 \\
\hline
\end{tabular}

достаточную тепловую энергию для роста на основных плоскостях с низкими индексами.

В таблице приведены характеристики пиков дифракции, параметр решетки и данные по $L_{\mathrm{CDA}}$. Период решетки изменялся в пределах от 0.4251 до $0.4240 \mathrm{~nm}$. Отжиг в вакууме с увеличением температуры приводит к уменьшению периода решетки пленок TiN. По-видимому, отжиг снижает остаточное внутренние напряжение и уменьшает концентрацию структурных дефектов в покрытиях [11,12]. Оценка размеров кристаллитов покрытия показывает, что увеличение температуры отжига приводит к изменению размеров зерна. В результате наблюдаемые изменения размеров кристаллитов покрытия являются результатом роста субзерен и миграции границ зерен, которые происходят во время отжига.

На рис. 2 приведены фрактограммы и морфология поверхности покрытий TiN на подложке из лейкосапфира до и после термической обработки в вакууме при температуре $600,700,800$ и $900^{\circ} \mathrm{C}$ в течение $2 \mathrm{~min}$. Фрактограммы излома (рис. 2, $a, c, e, g, i$ ) показывают, что покрытия состоят из вертикально ориентированных столбчатых зерен. По мере повышения температуры отжига происходит изменение плотности микроструктуры. Как видно из рис. $2, d, f, h, j$, морфология поверхности пленок TiN изменяется при термической обработке. Замечено, что при 800 и $900^{\circ} \mathrm{C}$ на поверхности покрытия TiN начинает расти хрупкий с низкой адгезией слой оксида титана в фазе рутила, который быстро разрушает защитную стойкость покрытия.

На рис. 3 показан микрорельеф поверхности пленок TiN. Исследование топографии поверхности пленок TiN показало, что поверхность синтезированной пленки имеет большую шероховатость $-7.42 \mathrm{~nm}$. Температура отжига незначительно влияет на микрорельеф поверхности пленок TiN. Минимальное значение шероховатости $3.48 \mathrm{~nm}$ наблюдается для пленок с температурой обработки $600^{\circ} \mathrm{C}$, а при $700^{\circ} \mathrm{C}$ шероховатость поверхности возрастает до $5.92 \mathrm{~nm}$.

\section{Заключение}

Получены результаты исследования температуры отжига на микроструктуру и морфологию пленок TiN, синтезированных на подложках лейкосапфира методом дуального магнетронного распыления. Установлено, что интенсивность рефлексов существенно изменяется с увеличением температуры отжига. Отмечено, что при 800 и $900^{\circ} \mathrm{C}$ на поверхности покрытия $\mathrm{TiN}$ начинает расти хрупкий с низкой адгезией слой оксида титана в фазе рутила. Период решетки пленок TiN уменьшается с увеличением температуры отжига. Такие закономерности связаны с уменьшением концентрации структурных дефектов и снижением остаточных внутренних напряжений.

Данные электронной микроскопии показали, что покрытия состоят из вертикально ориентированных столбчатых зерен, причем с увеличением температуры отжига плотности микроструктуры увеличиваются. В исследовании микрорельефа поверхности покрытий TiN установлено, что средние значения шероховатости зависят от температуры отжига.

Работа выполнена при финансовой поддержке гранта РФФИ (№ 14-41-08064 р_офи_м) и программы стратегического развития БГТУ им. В.Г. Шухова.

Авторы выражают благодарность $3 \mathrm{AO}$ „Монокристалл“ и ООО „БЗС „Монокристалл“ за помощь в проведении исследований.

\section{Список литературы}

[1] Wang X.C., Chen X.M., Yang B.H. // Sol. Stat. Sci. 2012. Vol. 14. N 4. P. $435-439$.

[2] Hongjian Guoa, Wenyuan Chen, Yu Shan, Wenzhen Wanga // Appl. Surf. Sci.: A. 2015. Vol. 357. P. 473-478.

[3] Arshi N., Lu J., Joo Y.K., Lee C.G., Yoon J.H., Ahmed F. // Mater. Chem. Phys. 2012. Vol. 134. N 2-3. P. 839-844. 
[4] Liqiang Zhang, Huisheng Yang, Xiaolu Pang, Kewei Gao // Surf. Coat. Technol. 2013. Vol. 224. P. 120-125.

[5] Lawand N.S., French P.J., Briaire J.J., Frijns J.H.M. // Proc. Engineer. 2012. Vol. 47. P. 726-729.

[6] Зайщев С.В., Колесник В.В., Ващилин В.С., Нарцев В.М., Прохоренков Д.С., Евтушенко Е.И. // Огнеупоры и техническая керамика. 2016. Т. 11-12. С. 22-25.

[7] Monshi A., Foroughi M.R., Monshi M.R. // World J. Nano Sci. Engineer. 2012. Vol. 2. P. 154-160.

[8] Vipin Chawla, Jayaganthan R., Ramesh Chandra // Bullet. Mater. Sci. 2009. Vol. 32. N 2. P. 117-123.

[9] Chou W.-J., Yu G.-P., Huang J.-H. // Surf. Coat. Technol. 2003. Vol. 168. N 1. P. 43-50.

[10] Yingxue Xi, Huiqing Fan, Weiguo Liu // J. Alloys and Compounds. 2010. Vol. 496. N 1-2. P. 695-698.

[11] Matsue T., Hanabusa T., Ikeuchi Y. // Thin Sol. Film. 1996. Vol. 281-282. N 1-2. P. 344-347.

[12] Arslan E., Efeoglu I. // Materials Characterization. 2004. Vol. 53 P. 29-34. 